\title{
Simulation of Saltwater Intrusion in Coastal Aquifer of Kg. Salang, Tioman Island, Pahang, Malaysia
}

\author{
Azrul Normi Idris ${ }^{1, *}$, Ahmad Zaharin Aris $^{2}$, Tahoora Sheikhy Narany ${ }^{2}$, Sarva Praveena \\ Mangala ${ }^{3}$, Saim Suratman ${ }^{1}$, Ismail Tawnie ${ }^{1}$, Mohd Khairul Nizar Shamsuddin ${ }^{1}$ and Anuar \\ Sefie $^{1}$ \\ ${ }^{1}$ Hydrogeology Research Center, National Hydraulic Research Institute of Malaysia (NAHRIM), Lot \\ 5377, Jalan Putra Permai, 43300 Seri Kembangan, Selangor, Malaysia \\ ${ }^{2}$ Environmental Forensics Research Centre (ENFORCE), Faculty of Environmental Studies, 43400 \\ UPM, Serdang, Selangor, Malaysia \\ ${ }^{3}$ Department of Environmental and Occupational Health, Faculty of Medical and Health Science, \\ 43400 UPM, Serdang, Selangor
}

\begin{abstract}
Numerical models are capable of simulating various groundwater scenarios and relate it towards groundwater management. A mesh based density dependent flow model, FEFLOW is used to simulate groundwater flow and transport for a coastal island aquifer in $\mathrm{Kg}$. Salang, Tioman Island, Malaysia. FEFLOW is designed to simulate 2D and 3D, variable density groundwater flow and multi-species transport. The impacts of pumping and recharge rates represented by three different groundwater scenarios, which were investigated by means of hydraulic heads, TDS concentrations and water balance components. Scenario A showed the standard saturated groundwater flow and the steady state fluid flow. Over pumping and inconsistency in recharge rate are the stresses shown in Scenarios B and C. Scenario B involved in the maximum pumping rate of $96 \mathrm{~m}^{3}$ per day and recharge rate of $300 \mathrm{~mm}$ per year has shown a drawdown of $1.5 \mathrm{~m}$. Scenario $\mathrm{C}$ showed the extreme pumping rate of $1000 \mathrm{~m}^{3}$ per day and without recharge has shown a decrease in groundwater levels of 6.3 m.and groundwater storage $(50 \%)$. Scenario B presented the most promising finding compared with Scenario C. Highest hydraulic heads, lowest mass concentration and positive groundwater storage $\left(2578.6 \mathrm{~m}^{3} /\right.$ day $)$ were obtained in Scenario B. Additionally, and further progress is needed in obtaining the water usage data from each part to determine the best pumping rate. A sustainable groundwater management plan is crucial to maintain the natural resources and social benefits as well as to protect the ecological balance.
\end{abstract}

* Corresponding author: azrul@nahrim.gov.my 


\section{Introduction}

The fresh water of small tropical islands is often very limited and mostly depend on recharge quantity and storage capability of groundwater resources [1]. Under natural conditions, there is an equilibrium between saltwater and freshwater. Seaward freshwater gradient gets reduced and even sometimes may be reversed to landward direction due to the excessive pumping activities. This leads to aggressive saltwater intrusion from the sea contaminating inland fresh water aquifers to a large extent which may take several years to get remediated [2]. The impact of climate change such as recharge rate and human pressure pumping rate on freshwater/groundwater have been controlling the shape and thickness of the freshwater lens [3]. To address this issue effectively, density dependent groundwater model is required to track the movement of the solute in coastal aquifers [4].

Previously study in $\mathrm{Kg}$. Salang using MODFLOW code for the groundwater storage study for alluvial aquifer in Tioman Island [5]. The study is to compare the pumping rate and the storage capacities in each of the village in Tioman Island. The advantage of FEFLOW software is the vast amounts of data generated from numerous sources in a variety of formats. Therefore, the objective of the present work is to use the FEFLOW code to develop a solute transport model for a coastal aquifer in Kg. Salang, Tioman Island, Malaysia and form the preliminary data for exploring the possibilities of further groundwater development for the region.

A 3D density-dependent transient flow and transport model has been implemented in order to evaluate the intrusion of seawater into the coastal freshwater aquifer [6]. In an unconfined aquifer that contacts the sea at the shoreline or seaward, the freshwater, which is less dense than seawater floats as a lens-shaped layer on top of seawater and the weight of the overlying freshwater depresses the seawater below sea level [7]. Generally, freshwater recharge in the aquifers moves down gradient and eventually discharges to lowlying coastal areas and into the sea which in turn can decrease or even reverse the seaward flow so that seawater moves landward into the freshwater aquifer known as seawater intrusion. The interface between the salty groundwater below and fresh groundwater above is a transition zone of gradually mixing fresh and salt waters. The location of the transition zone depends on several natural and human-made conditions: the relative densities of seawater and freshwater, the tides, the pumping from wells, the rate of groundwater recharge and the hydraulic features of the aquifer. According to the Ghyben-Herzberg Principle [8], salt water rises 40 meters for every 1 meter of freshwater depression and forms a cone of ascension.

An attempt has been made in the coastal island aquifers of Kg. Salang, Tioman Island to assess the ingress of saline water intrusion, where significant quantities of groundwater are drawn for various utilities like tourism industry and domestic utilities using numerical groundwater flow and solute transport model developed with FEFLOW code, using hydrogeological and hydrochemical data. The main objective of this study is the development of a saltwater intrusion prediction tool for the prevention of water pollution in tourism coastal regions.

\section{Methodology}

A FEFLOW model code was employed for the finite element subsurface flow and transport simulation system. For the purpose of modelling saltwater intrusion, three scenarios were used and compared for the mass concentration, groundwater flow, water table and groundwater storage capability. The model boundary was delineated by catchment area of Salang River. 


\subsection{Case Study}

\subsubsection{Site description}

The study area is located in the North West of, Tioman Island, Malaysia (10499'15'E $104^{\circ} 9^{\prime} 38^{\prime \prime} \mathrm{E}$ and $\left.2^{\circ} 52^{\prime} 10^{\prime \prime} \mathrm{E}-2^{\circ} 52^{\prime} 40^{\prime \prime} \mathrm{E}\right)$ covering an area of about $350,000 \mathrm{~m}^{2}$ as shown Fig. 1. The subsoil of the coastal plain surrounding the site is characterized by alluvial sands, shells and corals. Geology of Kg. Salang is characterized by two different rock type which is granite in the south and pyroxene hornfel in the north. Alluvium is found overlying the granite in the southern part of $\mathrm{Kg}$. Salang with about 4 to $30 \mathrm{~m}$ thick of medium to coarse sand with trace of corals and shells. The study area is underlain by unconfined aquifer comprising mainly of about $30.0 \mathrm{~m}$ thick medium to coarse sand confined to a narrow valley leading to the coast. These hydrogeological factors such as the permeability and porosity of the rocks and sediments have major influence on the distribution of groundwater on an island. Surface water resources prevail only on islands with relatively low permeability. Groundwater resources are most abundant on small islands with moderate to high permeability and porosity. Size, shape and topography of a small island influence the occurrence of both surface and groundwater resources. Since the area is located 50 metres from the coastline, groundwater flow and hydro-geochemistry is strongly influenced by seawater intrusion.

There are fifteen numbers of well scatter around the study areas. The wells were built in different method of drilling. The alluvial thickness is about 4 to $29 \mathrm{~m}$ thick from the bore $\log$ recorded. The groundwater flow from South east to the north west of the study area.

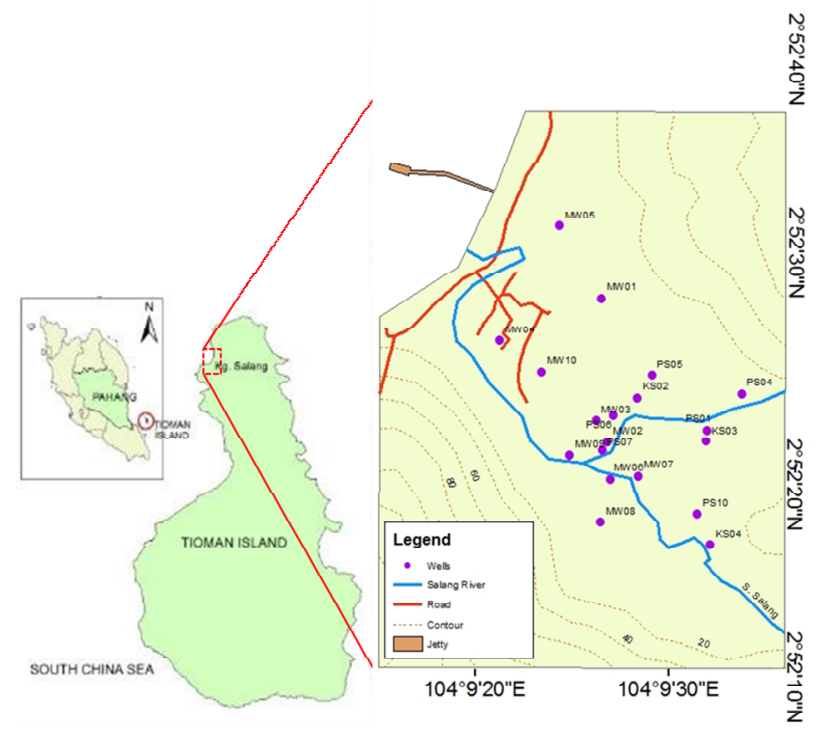

Fig. 1. Location map of wells in the study area

\subsubsection{Density-dependent flow approach}

In the low lying area of $\mathrm{Kg}$ Salang, Tioman Island from the hilly side to the shoreline was selected as study area (Fig. 1). Observation and abstraction wells are located on the low lying area ( 5 wells are currently operated and observed). There are different method of 
drilling were used to install the wells (washed boring, hand auger, jetting and hand dug caisson) and were distributed across the study area. Water level and mass concentration were observed and collected from April 2013 to February 2014 bi-monthly from the wells.

In the study, the hydraulic conductivity of horizontal and vertical direction was taken from the soil sample for the hydraulic conductivity and porosity analysis. The unconfined layer divided into 2 layer and 3 slices based on the hydrogeological information. Properties of $\mathrm{Kg}$ Salang, Tioman Island (Table 2) were assigned to the active model mesh. A TDS mass concentration of $35,000 \mathrm{mg} / \mathrm{L}$ was assigned for constant concentration and $0 \mathrm{mg} / \mathrm{L}$ for recharge concentration. In the study, the model calibration is achieved through trial and error approach by adjusting the value of conductivities and porosity until calculated values match the observed values. This method has been done in various groundwater model studies [9].

\subsubsection{Model development}

The groundwater flow has been simulated using the FEFLOW code [10], a modular three dimensional finite element groundwater flow model. The horizontal discretization of the unconfined aquifer was implemented using a triangular finite element mesh consisting of 111,378 mesh nodes and 148,234 mesh elements. The 3D numerical domain shows thickness of $38 \mathrm{~m}$ (from 0.5 to 35 m.s.l.) and the mesh boundary condition as in Fig. 2. It includes 2 layers ( $6 \mathrm{~m}$ of thickness) and 3 slices (or surfaces). The first and the last slices, represent the top and the bottom of the aquifer respectively, which have been produced using field data and kriging interpolation method. The model requires freshwater hydraulic heads as input, thus an equivalent hydraulic head needs to be calculated when applying boundary conditions and when comparing model results to field data [10]. A first type flow boundary condition was set along the coastline. For the first layer the hydraulic head at coastal area was set to zero and for the rest of the layers it was set as equivalent freshwater head, assuming a saltwater density of $1,025 \mathrm{~kg} / \mathrm{m}^{3}$ Pumping wells were defined as $4^{\text {th }}$ kind flow boundary conditions and their screens were set at the second layer. An average monthly infiltration rate was also included as an inflow parameter on the top layer of the model. A first type mass boundary condition was imposed along the coastline with a constant value of $35 \mathrm{~kg} / \mathrm{L}$ of TDS concentration. The porosity was estimated at 0.3 and the longitudinal and transverse dispersivities were 20 and $2 \mathrm{~m}$, respectively, based on model calibration. The model was run in transient mode for a period of 365 days. 


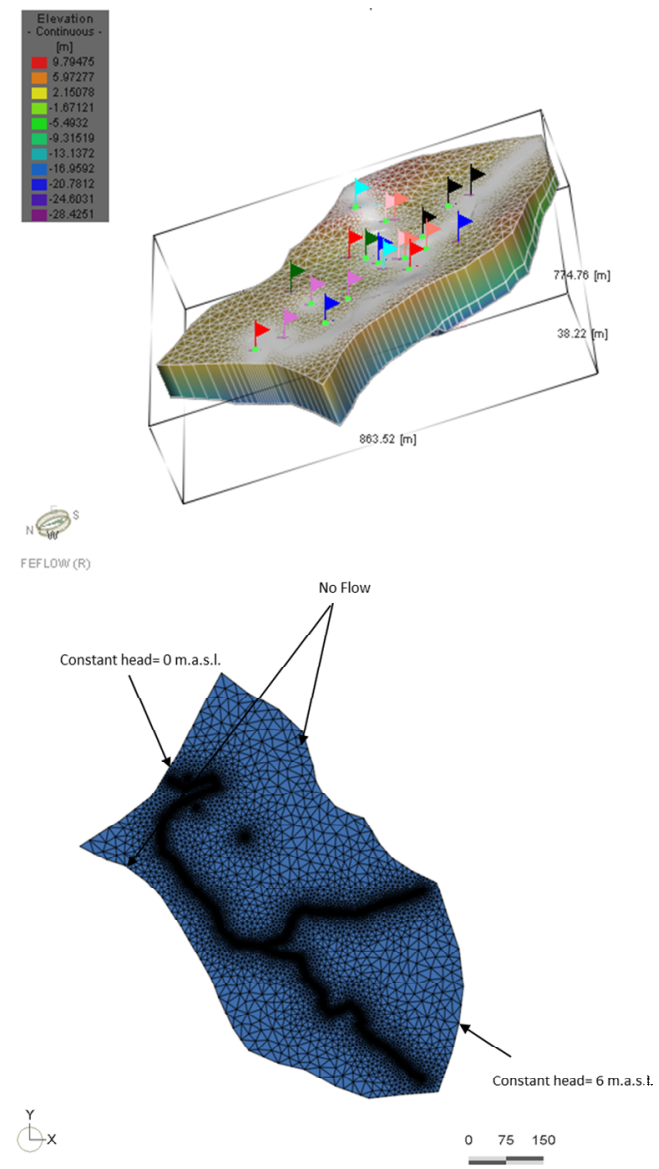

Fig. 2. Two layers and three slices of domain boundary and elevation of the study area (left), Mesh and boundary condition in the study area (right).

Constant values of hydraulic conductivity, derived from field data, characterize the whole domain: $\mathrm{K}_{\mathrm{x}}=\mathrm{K}_{\mathrm{y}}=4.5 \times 10-4 \mathrm{~m} / \mathrm{s}, \mathrm{K}_{\mathrm{z}}=1.8 \times 10-5 \mathrm{~m} / \mathrm{s}$. These values were evaluated in the sensitivity analysis. The system is influenced by the following physical boundaries: the sea (inflow-outflow), the up-stream hydraulic head (inflow), the pumping wells of the hydraulic barrier and the water supply wells (outflow). Recharged in the study area was calculated by a modified version of Chaturvedi [11] for tropical regions based on water level fluctuation and rainfall depths as given in Equation 1,

$$
R=1.35[(P-14)]^{0.5}
$$

where, $\mathrm{R}$ is the net recharge and $\mathrm{P}$ is the annual precipitation in inches. The amount of recharge coefficient is defined as the ratio of recharge to effective rainfall [12]. The range of recharged varied from 215 to $308 \mathrm{~mm} /$ year. Fig. 3 show the flow chart of FEFLOW that including a conceptual model, finite element mesh (FEM), problem setting, model properties, simulation scenarios and output of model. The flow boundary conditions were assigned as specified in the previous paragraph; the hydraulic head was assigned to the sea considering the difference of density between sea-water and freshwater (density ratio). The TDS transport boundary conditions assumes the following constant concentration of TDS up gradient constant concentration of TDS is $0 \mathrm{mg} / \mathrm{L}$; down gradient constant concentration 
of TDS: is $35 \mathrm{~kg} / \mathrm{L}$. The static water table has been given as initial head. A $0 \mathrm{mg} / \mathrm{L}$ initial concentration of TDS has been assigned.

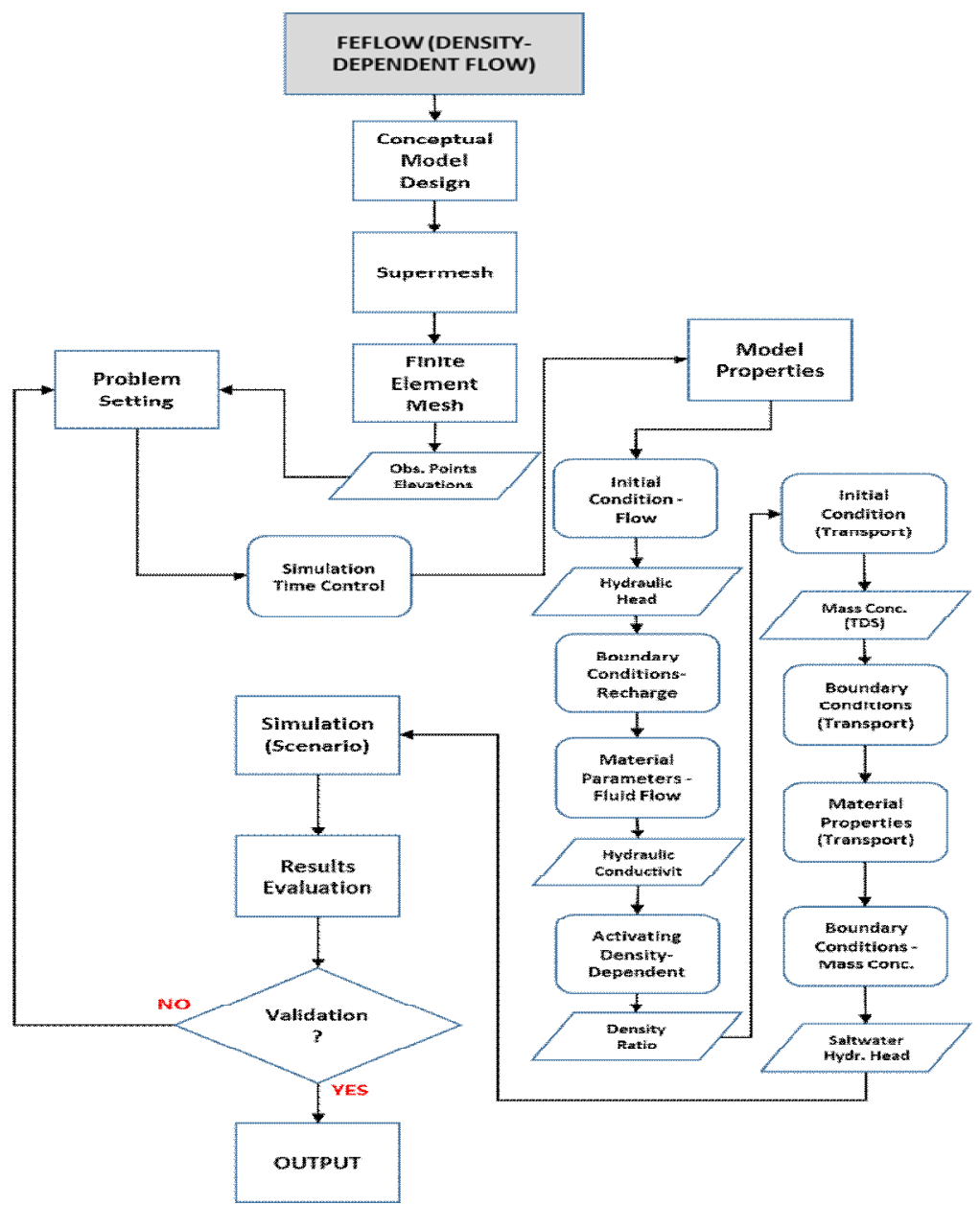

Fig. 3. FEFLOW Numerical modeling procedures flow chart

\subsection{Boundary conditions and materials properties of flow and mass}

The summary of the model physical parameters and data input for the boundary condition and properties were shown in Table 1. One the model was calibrated; it was run for verify the various scenarios where the predictive simulations were performed to minimize overabstraction in the unconfined aquifer (Table 2). The simulations were done to predict the aquifer response toward the pumping activities (pumping rate) by human pressures on the freshwater resources. The scenarios will be focusing in the pumping rate to meet the needs of water supply for domestic and tourism industries in the study area. 
Table 1. Parameters and model boundaries input data

\begin{tabular}{|c|c|}
\hline Parameter & Value \\
\hline \multicolumn{2}{|l|}{ Physical Parameters } \\
\hline \multicolumn{2}{|l|}{ Grid/Mesh } \\
\hline Element type & Triangle prism \\
\hline Mesh element & 148,234 \\
\hline Mesh Node & 111,378 \\
\hline Number of layer & 1 \\
\hline Number of slice & 2 \\
\hline Total model boundary areas & $343,298 \mathrm{~m} 2$ \\
\hline \multicolumn{2}{|l|}{$\begin{array}{l}\text { Materials Properties and Boundary Conditions } \\
\text { (BC) }\end{array}$} \\
\hline Hydraulic Conductivity, $\mathrm{Kx}, \mathrm{Ky}, \mathrm{Kz}$ & $\begin{array}{l}4.5 \times 10-4 \mathrm{~m} / \mathrm{s}, 4.5 \times 10-4,1.8 \times 10-5 \\
\mathrm{~m} / \mathrm{s}\end{array}$ \\
\hline Specific storage (Fluid flux) & 0.002 \\
\hline Total Porosity & 0.35 \\
\hline Longitude dispersivity & $1 \mathrm{~m}$ \\
\hline Tranverse dispersity & $0.1 \mathrm{~m}$ \\
\hline Density ratio & $1,025 \mathrm{~kg} / \mathrm{m} 3$ \\
\hline Constant head & $0 \mathrm{~m}$ \\
\hline Recharge concentration & $0 \mathrm{mg} / \mathrm{L}$ \\
\hline Constant head concentration & $35,000 \mathrm{mg} / \mathrm{L}$ \\
\hline Initial concentration & Based on April 2013 \\
\hline Initial head & Based on April 2013 \\
\hline
\end{tabular}

Table 2. Three scenarios for the simulation of saltwater intrusion.

\begin{tabular}{|l|l|}
\hline Simulation & \multicolumn{1}{|c|}{ Description } \\
\hline Scenario A & $\begin{array}{l}\text { In the steady state of fluid and transport groundwater flow (without } \\
\text { pumping) }\end{array}$ \\
\hline Scenario B & $\begin{array}{l}\text { The recharge rate of } 300 \mathrm{~mm} \text { per year and maximum pumping rate } \\
96 \mathrm{~m}^{3} / \text { day }\end{array}$ \\
\hline Scenario C & $\begin{array}{l}\text { The recharge rate of } 0 \mathrm{~mm} \text { per year and maximum pumping rate of } \\
1000 \mathrm{~m}^{3} / \text { day.(transient of } 365 \text { days simulation time). }\end{array}$ \\
\hline
\end{tabular}

\section{Results and Discussions}

\subsection{Calibration and Sensitivity Analysis}

The sensitivity analysis was performed in order to understand the uncertainties caused by the estimates of the aquifer parameters, stresses and boundary conditions. Hydraulic head and dispersivity were varied during the sensitivity analysis for hydraulic conductivity as shown in Fig. 4. The calibration procedure consists in modifying the aquifer parameters and the boundary conditions in order to obtain a model suitable to simulate the groundwater flow and the mass concentration distribution, within the calibration target. In the calibration process, a trial and error procedure has been carried out in order to minimize the difference between the simulated and the measured levels/concentrations (residuals).

The transient model development has been based on the 3D steady-state flow model and takes into account the anthropogenic pressure due to pumping wells on the aquifer. Because of the complexity of the site, a 2D model has been implemented along a section perpendicular to the coast. This approach allowed estimating the longitudinal and 
transverse dispersivity of the total dissolved salt (TDS) in the aquifer. These parameters are usually site-specific, obtained by tracer tests. Since tracer tests were not performed, this step is important to calibrate the aquifer dispersivity. Scenario A and scenario B show slightly drop of water table varies from 0.01 to $0.04 \mathrm{~m}$ and scenario $\mathrm{C}$ drop from 0.05 to $0.22 \mathrm{~m}$ (Fig. 5). This was due to the abstraction of $1,000 \mathrm{~m} 3 /$ day from well, SW03. Table 3 shows the ability of storage after three different scenarios with pumping. Scenario B is the optimum pumping rate with small amount of groundwater abstraction with average of 1.5 m drawdown.

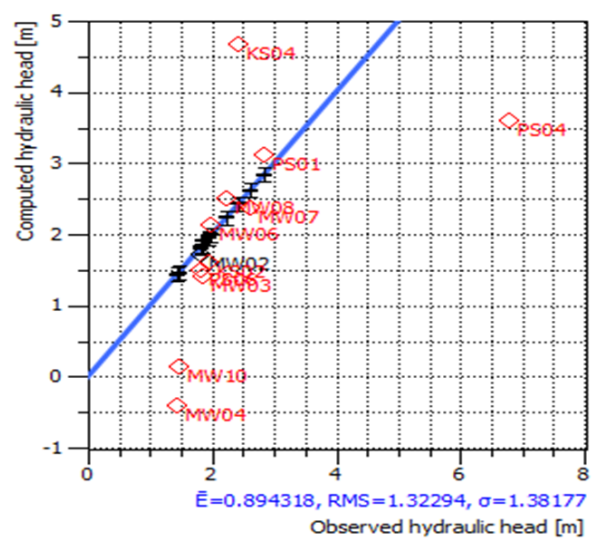

Fig. 4. Comparison of measured and computed hydraulic head values.

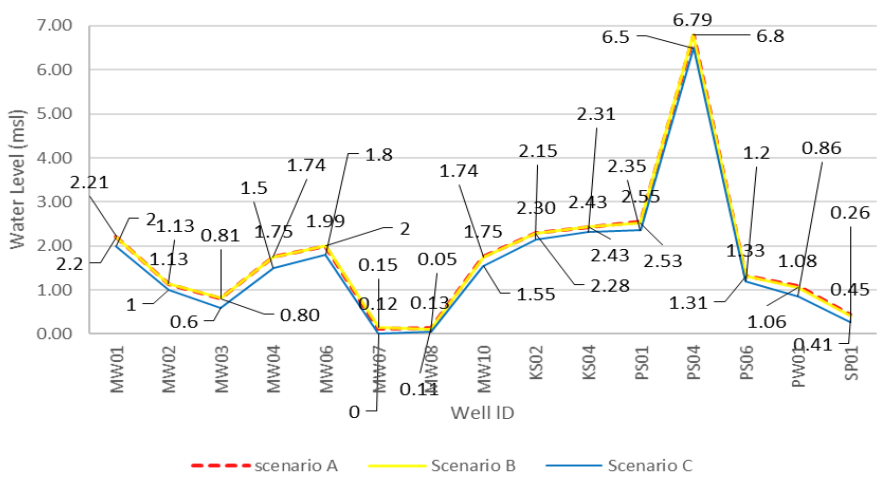

Fig. 5. Decline in ground water levels due to the different scenarios.

Table 3. Simulation after the scenarios of the capture storage.

\begin{tabular}{|l|c|c|}
\hline Scenario & Storage Capture $\left(\mathbf{m}^{\mathbf{3}} / \mathbf{d}\right)$ & Groundwater Abstraction \\
\hline Scenario A & $2,983.5$ & 0 \\
\hline Scenario B & $2,578.6$ & 96 \\
\hline Scenario C & $1,788.3$ & 1000 \\
\hline
\end{tabular}

Maximum salinity was found $50 \mathrm{~m}$ from the coast line. Distance of the concentration were then measured are found that scenario $\mathrm{C}$ reach $1,000 \mathrm{mg} / \mathrm{L}$ concentration at $225 \mathrm{~m}$ from the coast. 
Table 4. Movement of mass concentration into the aquifer based on the simulation.

\begin{tabular}{|l|c|c|}
\hline Scenario & Maximum salinity (20-50)m from & Distance from coast (m) with \\
\hline Scenario A & 680 & 30 \\
\hline Scenario B & 1,850 & 60 \\
\hline Scenario C & 10,000 & 225 \\
\hline
\end{tabular}

\section{Conclusions}

Seawater intrusion may further advance inland if withdrawals of groundwater by builders, resorts and others tourism activities continue to increase in the coming years. Groundwater quality need to be continuously be monitored near the coastal area, within $100 \mathrm{~m}$ from the coast. The effect of seawater intrusion on fresh groundwater in coastal areas requires thorough examination, especially when the withdrawal for water supply in the coastal areas increases. An attempt has been made in the present study area to demarcate the saline influences by hydrochemistry and modeling approach.

\section{References}

[1] A.Z. Aris, M.H. Abdullah, and B. Musta. Hydrochemical Analysis on Groundwater in Shallow Aquifer of Manukan and Mabul Island, Malaysia. International Association of Hydrological Science Red Book (IAHS) Publication, 319, 387-394, (2008)

[2] S.M. Praveena, M.H. Abdullah, A.Z. Aris, L.C. Yik and K. Bidin. Numerical Modelling of Seawater Intrusion in Manukan Island's Aquifer. World Applied Sciences J., 14, 1-7, (2011)

[3] S.M. Praveena and A.Z. Aris. Groundwater Resources Assessment Using Numerical Model: A Case Study in Low-Lying Coastal Area. Int. J. Enviroment. Science. Technology, 7(1), 135-146, (2010)

[4] J. Lin, J.B Snodsmith, C. Zheng, and J. Wu. A Modeling Study of Seawater Intrusion in Alabama Gulf Coast, USA. Environmental Geology, 57, 119-130, (2009)

[5] N.A. Ahmad Abdul Ghani, Groundwater Study for Alluvial Aquifer in Tioman Island. MSc. Thesis. Universiti Teknologi Malaysia, 187, (2004).

[6] P. Aitchison-Earl, M. Ettema, C. Hanson, S. Hayward, R. Larking, R. Sanders, and A. Veltman. Coastal Aquifer Saltwater Intrusion Assessment Guidelines. Report No. R04/18, (2003)

[7] E.D.P. Perera, K. Jinno, A. Tsutsumi, and Y. Hiroshiro. Development and Verification of A Three Dimensional Density Dependent Solute Transport Model for Seawater Intrusion. Memoirs of the Faculty of Engineering, Kyushu University. 68, 93-106 (2008)

[8] J. Bear. Seawater Intrusion in Coastal Aquifers: Concepts, Methods and Practices. Boston Mass: Kluwer Academic, (1999)

[9] R. Rejani, M.K. Jha, S.N. Panda and R. Mull. Simulation Modelling for Efficient Groundwater Management in Balasore Coastal Basin, India. Water Resources. Management., 22(1), 23-50 (2008)

[10]H.J.G. Diersch. FEFLOW: Finite Element Modelling of Flow, Mass and Heat Transport in Porous and Fractured Media. Springer Heidelberg New York Dordrecht London (2014) 
[11]R.S. Chaturvedi. A Note on The Investigation of Groundwater Resources in Western Districts of Uttar Pradesh. In Anuual Report. U.P. Irrigation Research Institute., 86122, (1973)

[12]B.D.R. Misstear, I. Brown, and D. Daly. A Methodology for Making Initial Estimates of Groundwater Recharge From Groundwater Vulnerability Mapping. Hydrogeology J., 17(2), 275-285, (2009) 